\title{
SEQUÊNCIA DIDÁTICA DE CIÊNCIAS PARA DEBATER O TEMA ALIMENTAÇÃO NOS ANOS INICIAIS DO ENSINO FUNDAMENTAL
}

\author{
Leonardo Salvalaio Muline1, Sidnei Quezada Meireles Leite², Carlos Roberto Pires Campos ${ }^{3}$
}

\author{
Programa de Pós-graduação em Educação em Ciências e Matemática \\ Instituto Federal do Espírito Santo \\ Av. Vitória, 1729 -Prédio Administrativo, Programa Educimat, \\ Bairro Jucutuquara, Vitória, Espírito Santo. CEP 29040-780.
}

\begin{abstract}
RESUMO
Atividades escolares que buscam um ensino de Ciências mais comprometido com a realidade do educando devem ser capazes de promover a alfabetização científica desses sujeitos, no intuito de melhorar suas relações com o meio em que vivem e torná-los capazes de fazer uma leitura mais crítica do seu cotidiano. Desta forma, este trabalho tem como objetivo propor uma sequência didática para o debate do tema Alimentação Humana, com atividades baseadas na realidade dos alunos, comprometido com a perspectiva do movimento CTSA (Ciência, Tecnologia, Sociedade e Ambiente) e pautada por princípios da Pedagogia Histórico-Crítica. 0 público alvo são os adolescentes do oitavo ano do ensino fundamental das séries finais. Acreditamos que inserir essas práticas dentro do ensino de Ciências, com posturas diferenciadas e com práticas pedagógicas atrativas para os alunos, os mesmos terão a possibilidade de construir, desconstruir e reconstruir os seus próprios conhecimentos.
\end{abstract}

Palavras-chave: sequência didática; alfabetização científica; ensino de Ciências.

\begin{abstract}
School activities that seek a science teaching more committed to the reality of the student must be able to promote the scientific literacy of the subjects, in order to improve its relations with the environment they live in and make them able to make a more critical reading of the their daily lives. Thus, this paper aims to propose a didactic sequence for the discussion of the topic Human Food, with activities based on the reality of students, committed to the perspective of the movement STSE (Science, Technology, Society and Environment) and guided by principles of Pedagogy historical and Critical. The target audiences are teenagers in the eighth year of the final grades of elementary school. We believe that these practices enter into the teaching of science, with different attitudes and pedagogical practices attractive to students, they will be able to construct, deconstruct and reconstruct their own knowledge.
\end{abstract}

Keywords: didactic sequence; scientific literacy; science teaching.

\footnotetext{
1 Professor de ciências biológicas, M.Ed. - Professor do Instituto Federal do Fluminense - Campus Macaé. E-mail: leonardosalvalaio@gmail.com.

2 Professor de educação em ciências e química, D.Sc. - Professor permanente do Programa de Pós-graduação em Educação em Ciências e Matemática do Instituto Federal do Espírito Santo, Cefor. E-mail: squezada@ifes.edu.br 3 Professor de educação, D.L. - Professor permanente do Programa de Pós-graduação em Educação em Ciências e Matemática do Instituto Federal do Espírito Santo, Cefor. E-mail: carlosr@ifes.edu.br
} 


\section{INTRODUÇÃo}

Nos dias de hoje, dificilmente, iremos encontrar uma pessoa que consiga viver sem precisar de alguma invenção da ciência. Para grande parte das atividades que nos propomos a realizar em nosso cotidiano, de alguma forma, direta ou indiretamente, estamos utilizando algum conhecimento científico. Entretanto, grande parcela da população que usa essas tecnologias não faz ideia de como ela foi criada ou foi descoberta, ou até mesmo desconhece o mecanismo que faz com que determinado aparelho funcione. Aliás, a maioria esmagadora possui a representação que esse tipo de conhecimento é para poucos e que somente pessoas portadoras de certas habilidades podem ter acesso a essas informações, ou seja, elas usam o objeto, mas não sabe como aquilo foi desenvolvido.

Por isso, ao longo dos últimos anos, a preocupação com o nível de conhecimento sobre ciência e tecnologia da população se intensificou no mundo todo e, em especial, no Brasil (KRASILSHIK \& MARANDINO, 2007, p. 19). Esse tipo de assunto tem promovido uma série de mudanças por partes de diferentes setores que formam a nossa sociedade no sentido de oportunizar um maior acesso para os cidadãos sobre os assuntos relacionados à ciência, já que vivemos atualmente num mundo notadamente influenciado pela ciência e pela tecnologia (SANTOS \& MORTINER, 2002, p. 2).

Nesse sentido, o ensino de Ciências preocupado com essas questões, torna-se força potencial para a promoção da quebra de paradigmas que são necessárias para criarmos uma população alfabetizada cientificamente. Contudo, o rótulo alfabetização científica e tecnológica abarca um leque bastante amplo de significados traduzidos por meio de expressões como popularização da ciência, divulgação científica, entendimento público da ciência e democratização da ciência (AULER \& DELIZOICOV, 2001, p. 2). Para CHASSOT (2003, p. 91), alfabetização científica pode ser considerada umas das dimensões para potencializar alternativas que privilegiam uma educação mais comprometida.

Assim, poderíamos pensar que a alfabetização científica signifique possibilidades de que a grande maioria da sociedade disponha de conhecimentos científicos e tecnológicos necessários para se desenvolver na vida diária, ajudar a resolver os problemas e as 
necessidades de saúde e de sobrevivência básica, tomar consciência das complexas relações entre ciência e sociedade (FURIÓ et al., 2001 apud CHASSOT, 2003, p. 97).

Carvalho (2010, p. 3) nos remete ao fato de que não se pode, hoje, conceber o ensino de Ciências sem que este esteja vinculado às discussões sobre os aspectos tecnológicos e sociais que essa ciência traz, com vistas à modificação de nossas sociedades. Além disso, é preciso que os professores saibam construir atividades inovadoras que levem os alunos a evoluírem, em seus conceitos, habilidades e atitudes, mas é preciso também que eles saibam dirigir os trabalhos dos alunos para que estes realmente alcancem os objetivos propostos (CARVALHO, 2010, p. 9), já que formar, como nos lembra FREIRE (2003, p. 14), é muito mais que puramente treinar o educando no desempenho de destrezas.

Entretanto, o que observamos na contemporaneidade, na maioria das vezes, é um ensino de Ciências ainda preso ao tradicionalismo, ou seja, um processo predominantemente voltado para a fragmentação do conhecimento, em que a proposta pedagógica ainda está atrelada aos interesses de uma elite dominante, favorecendo a homogeneização dentro do contexto educacional brasileiro. No que se refere às disciplinas científicas, o que se nota é que o foco ainda é a valorização do conteúdo exarcebado dos conhecimentos específicos de cada área, não oportunizando uma articulação entre os diversos campos do saber. Além disso, muitos educadores não conseguem fazer uma contextualização com o cotidiano do educando, ou seja, não ocorre a significação do processo de ensino e de aprendizagem. Com isso, podemos entender que o ensino de Ciências trabalhado em nossas salas de aula acaba distanciando o indivíduo do trabalho do cientista, criando uma ideia de que a ciência é para poucos e somente pessoas portadoras de certas qualidades podem ter acesso a esses conhecimentos, como mencionado anteriormente.

$\mathrm{Na}$ verdade, esse tipo de ensino que é oferecido não atende às atuais demandas da nossa sociedade. Por isso, são necessárias mudanças urgentes nas propostas educacionais dentro do ensino de Ciências para que elas sejam pautadas por princípios democráticos, inovadores e emancipadores, vinculados aos interesses das sociedades, em que o saber atinja as diversas camadas populares e haja entendimento da realidade histórica e os problemas sociais sejam discutidos. 
Nesse sentido, a Pedagogia Histórico-Crítica e o Movimento CTSA (Ciência, Tecnologia, Sociedade e Ambiente) são excelentes formas para se discutir essa quebra de paradigmas dentro do contexto educacional brasileiro e inserir um ensino de Ciências comprometido com a formação de um cidadão capaz de realizar uma leitura crítica do mundo em que vive. Teixeira (2003, p. 180) nos atenta para o fato de que a Pedagogia Histórico-Crítica entende a educação no sentido da sociedade humana e como os indivíduos podem se organizar para que ocorra um processo de transformação social. Ela compreende que a prática social é o ponto de partida e o ponto de chegada do processo de ensino. A partir das práticas sociais do aluno é que o educador encontrará os conteúdos importantes para um trabalho eficaz, ou seja, deve haver uma contextualização a partir do que acontece no meio em que vive o educando. $\mathrm{Na}$ verdade, a escola seria um ponto essencial para a democratização dos conhecimentos e a inserção de indivíduos mais críticos na sociedade. No que se refere ao movimento CTSA, é bastante evidente a sua importância dentro das práticas pedagógicas para a formação de pessoas que possam fazer uma leitura crítica do mundo que habitam. É necessário fomentar um ensino de Ciências que prepare os cidadãos para lidarem com responsabilidade com as questões sociais relativas à ciência.

Nesse aspecto, o objetivo desse trabalho é propor uma sequência didática para que o professor tenha a oportunidade de trabalhar o tema Alimentação Humana dentro de uma perspectiva do movimento CTSA, procurando inserir no ensino de Ciências uma postura diferenciada, longe de práticas pedagógicas obsoletas, e que permitam ao educando a possibilidade de construção, desconstrução e reconstrução dos seus conhecimentos, gerando uma mudança de conceitos e de atitudes, ou seja, um ensino de Ciências que leve à investigação e a contextualização do que o aluno vivencia, tentando, com isso, alcançar uma educação mais comprometida.

\section{PERCURSO METODOLÓGICO}

A sequência didática em questão está organizada baseada nos três momentos pedagógicos bem definidos, conforme nos orienta Delizoicov et al (2011), que são: Problematização do tema (P), Organização do conhecimento (O) e Aplicação do conhecimento (A)(Quadro 1). Esse modelo tem como objetivo contemplar a dimensão dialógica do processo educativo proposto por Paulo Freire (LEITE et al, 2012, p. 42). 
O público alvo seriam os educandos do oitavo ano do ensino fundamental das séries finais e o tempo de duração sugerido seria de 8 (oito) aulas de cinquenta minutos cada. Abaixo, segue uma tabela (TABELA 1) resumida das atividades propostas para a realização das atividades, juntamente com o número de aulas e os momentos pedagógicos em que cada uma está inserida.

Quadro 1. Atividades propostas da sequência didática para discutir o tema Alimentação Humana.

\begin{tabular}{|c|c|c|}
\hline $\begin{array}{c}\text { NÚMEROS } \\
\text { DE AULAS } \\
\text { PROPOSTAS }\end{array}$ & $\begin{array}{l}\text { MOMENTOS } \\
\text { PEDAGÓGICOS }\end{array}$ & ATIVIDADES PROPOSTAS \\
\hline 2 & \multirow[t]{2}{*}{$\mathrm{P}$} & $\begin{array}{l}\text { Exibição do filme: Super Size Me - A dieta do palhaço } \\
\text { (Duração do filme: } 1 \text { h e } 38 \text { min) }\end{array}$ \\
\hline 1 & & Debate sobre o filme \\
\hline \multirow[t]{3}{*}{2} & \multirow{3}{*}{0} & $\begin{array}{c}\text { Aula expositiva: Nutrientes e suas funções. Os alimentos e a } \\
\text { energia. A dieta saudável. }\end{array}$ \\
\hline & & $\begin{array}{c}\text { Atividade prática investigativa: verificando a presença do } \\
\text { amido nos alimentos }\end{array}$ \\
\hline & & $\begin{array}{c}\text { Leitura e discussão do texto: Aditivos alimentares } \\
\text { (laboratório de informática) }\end{array}$ \\
\hline & \multirow[t]{2}{*}{ A } & $\begin{array}{c}\text { Relatório das aulas práticas em grupos de no máximo } 4 \\
\text { alunos }\end{array}$ \\
\hline & & Trabalho: Agenda da Alimentação \\
\hline
\end{tabular}

\section{PROBLEMATIZAÇÃO}

O educador deverá organizar a sala para que os alunos assistam ao DVD título original "Super Size Me", em português o título do filme é "A Dieta do Palhaço". O professor para esta atividade poderá utilizar a sala de vídeo ou a própria sala de aula, se neste local for acessível uma televisão com um aparelho de DVD ou até mesmo um computador e data show. Embora o filme tenha seu foco em um problema tipicamente norte-americano, qual seja, a crescente onda de obesidade nos Estados Unidos, podemos nos basear nesta realidade, também, para denunciar o crescente consumo de comida tipo fast food pela população brasileira.

A sinopse do filme é a seguinte: O diretor Morgan Spurlock decide ser a cobaia de uma experiência: se alimentar apenas em restaurantes da rede McDonald's, realizando neles três 
refeições ao dia durante um mês. Durante a realização da experiência o diretor fala sobre a cultura do fast food nos Estados Unidos, além de mostrar em si mesmo os efeitos físicos e mentais que os alimentos deste tipo de restaurante provocam.

Após assistir ao filme, o professor deverá propor aos alunos que façam grupos para a resolução das questões sobree ele referentes. Ao término da atividade, esta deverá ser entregue em folha separada, para o professor, o qual deverá organizar um debate sobre essas atividades. A resolução das questões em grupos permitirá que os alunos discutam entre eles a respeito do próprio hábito alimentar. Vale ressaltar que é necessário que o grupo converse e exponha suas ideias até mesmo para repensar a respeito das dietas de cada componente. Durante a realização dessa tarefa, o docente deve avaliar os alunos, pois entendemos que a avaliação é um processo e deve permear todas as etapas da sequência didática. A sugestão de roteiro de questionamentos referentes ao filme foi baseada na que se encontra no seguinte endereço etronico: http://portaldoprofessor.mec.gov.br/fichaTecnicaAula.html?aula=20840):

O filme direciona o olhar para uma rede de comida fast food americana que criou tamanhos exagerados de porções e, sempre que possível, induz ao consumo de mais e maiores porções, o que estimula a população a consumir muito além do necessário para uma alimentação saudável. Você tem o hábito de se alimentar em locais que servem alimentos conhecidos como fast food? Qual a sua opinião em relação à comida fast food?

1. É comum encontrarmos vários estabelecimentos de comida fast food na cidade onde moramos ou em nossa região. Os grandes problemas desses alimentos estão na qualidade e no preparo. Diante deste fato, comente sobre a necessidade desta cultura alimentar "fast food" ser uma questão de saúde pública.

2. Por que será que as comidas tipo "fast food" não possuem uma tabela nutricional dos alimentos que são consumidos?

3. Como anda a sua alimentação? Você prioriza produtos naturais ou industrializados? Faça uma reflexão da sua alimentação com relação a alimentação apresentada no filme e discuta em sala de aula.

4. Discuta com o grupo a seguinte frase: "Uma pessoa obesa é uma pessoa bem nutrida? 
Esse tipo de atividade para iniciar um tema vai ao encontro do que Delizoicov et al (2011, p. 197) nos atenta, pois, para ele, problematiza-se, de um lado, o conhecimento sobre as situações significativas que vai sendo explicitado pelos alunos. De outro, identificam-se e formulam-se adequadamente os problemas que levam à consciência e necessidade de introduzir, abordar a apropriar os conhecimentos científicos. Esse binômio permite que os conhecimentos problematizados sirvam de ponto de ancoragem para os conhecimentos que serão construídos por meio da reflexão.

\section{ORGANIZAÇÃO DO CONHECIMENTO}

Nesse segundo momento pedagógico, um conjunto de atividades será oferecido aos alunos. A primeira delas é a aula expositiva, em que o professor trabalhará o conhecimento científico propriamente dito sobre a temática em questão (Figura 1). A introdução de estratégias de ensino diferenciadas não elimina a necessidade de se ter um momento de aula, abordando os conteúdos programáticos previstos no plano de aula (LEITE et al., 2012, p. 45). 0 mapa conceitual abaixo (FIGURA 1) pretende orientar o professor sobre quais conceitos são importantes para que o professor trabalhe durante as aulas sobre o tema.

A segunda parte desse momento pedagógico será a realização de uma aula prática investigativa para descobrir a presença do amido nos alimentos. 0 docente pode realizar essa atividade no laboratório de ciências ou até mesmo na própria sala de aula. Essa tarefa foi retirada do livro Projeto RADIX - raiz do conhecimento do oitavo ano do ensino fundamental. O professor deve começar a atividade levantando hipóteses para perceber os conhecimentos prévios dos alunos sobre o assunto. Indagações do tipo: cite alguns alimentos que você consome em seu dia a dia; em sua opinião, qual alimento citado por você contém mais amido? E quais desses alimentos não são ricos em amido? são essenciais para instigar nos educandos a curiosidade em descobrir em quais alimentos o amido é encontrado em maior ou menor quantidade. 
FIGURA 1: Mapa conceitual mostrando os temas possíveis de trabalho.

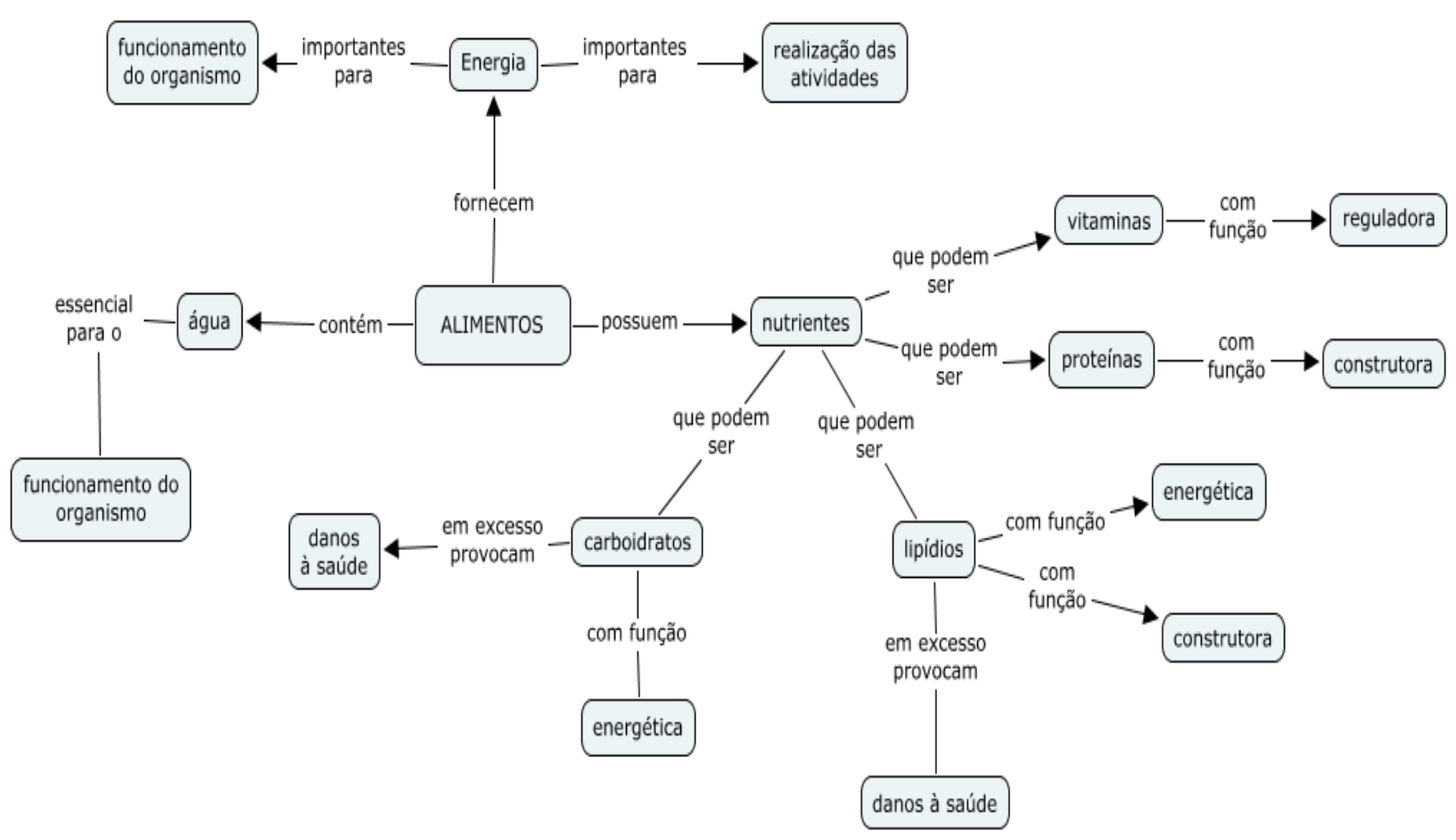

Fonte: Pesquisa dos autores.

Dando prosseguimento à tarefa, o educador deverá separar a turma em grupos de 2, 3 ou 4 alunos e pedir para que as equipes tragam os seguintes materiais que serão necessários para a aula: 1 faca sem ponta, iodo (que pode ser comprado em farmácia, 1 conta-gotas, 1 fatia de pão, 1 batata, 1 bolacha de água e sal, 1 ovo de galinha, 1 maça, $50 \mathrm{~mL}$ de leite, 1 panela, água, 1 garfo, 1 colher de sopa, 6 copos plásticos descartáveis (com capacidade para $180 \mathrm{~mL}$ ), 6 palitos de sorvete ou colheres de sobremesa, 1 folha de papel, fita adesiva e tesoura sem ponta.

Os procedimentos para a realização da atividade serão os seguintes: a) com a tesoura, recorte seis pedaços de papel, formando etiquetas. Escreva o nome dos alimentos que serão utilizados nesta atividade. Cole as etiquetas em cada um dos copos. b) Peça para um adulto cozinhar a batata. Após o cozimento, deixe-a esfriar para utilizá-la no experimento. c) corte 1/3 da batata cozida e amasse-a com um garfo em um copo descartável. d) Quebre metade da bolacha de água e sal até obter pedaços pequenos e coloque-os dentro de um copo plástico. e) Despedace $1 / 4$ da fatia de pão até obter pequenos pedaços e coloque-os em outro copo plástico. f) com a faca sem ponta, corte uma fatia de maçã e, com a colher, raspe-a dentro de outro copo plástico. 
g) Coloque o leite em outro copo plástico, até ocupar $1 / 3$ de sua capacidade. h) quebre o ovo e despeje a clara dentro de outro copo plástico até atingir a quantidade aproximada dos outros alimentos. i) em cada copo plástico que contém um alimento, coloque 3 colheres de sopa de água e misture bem com um palito de sorvete. j) coloque os 6 copos um ao lado do outro e, com o conta-gotas, pingue 5 gotas de iodo sobre cada um deles. Observe e anote o que aconteceu. k) em seguida, misture bem o iodo com o alimento e observe novamente. Anote em seu caderno o que você observou.

Finalizada essa parte, os alunos responderão, após os debates e as observações, às seguintes perguntas: 1) 0 que você observou ao realizar o item J do experimento? 2) Qual a função do iodo nesse experimento? 3) Qual foi o alimento que mais reagiu com o iodo? Por quê? 4) Houve reação do iodo com todos os alimentos? Explique. 5) 0 que você observou no item $\mathbf{K}$ do experimento? Explique. 6) Relacione o que você observou neste experimento com as questões propostas no início da nossa aula prática. 7) Troque ideias com os componentes do seu grupo e discutam sobre o que vocês concluíram quanto à quantidade de amido presente nesses alimentos.

Para que uma atividade possa ser considerada uma atividade de investigação, a ação do aluno não deve se limitar apenas ao trabalho de manipulação ou observação, ela deve também conter características de um trabalho científico: o aluno deve refletir, discutir, explicar, relatar, o que dará ao seu trabalho as características de uma investigação científica (AZEVED0, 2010, p. 21). Para Trazzi et al (2012, p. 31), o objetivo da experimentação nas aulas de ciências é o de verificação/comprovação de conceitos apresentados nas aulas teóricas. Além disso, professores costumam relatar que a experimentação é uma atividade fundamental no ensino de Ciências, pois pode despertar o interesse entre alunos de diversos níveis de escolarização, devido ao seu caráter motivador e lúdico (GIORDAN, 1999 apud TRAZZI et al, 2012, p. 31).

A outra atividade desse momento pedagógico é a leitura e a discussão do texto sobre os Aditivos Alimentares, da Revista Eletrônica de Química, uma publicação da Universidade Federal de Santa Catarina. Esse artigo está disponível no seguinte endereço eletrônico: http://qmc.ufsc.br/qmcweb/artigos/aditivos.html. Essa tarefa pode ser realizada no laboratório de informática da escola. Os alunos devem formar duplas e realizar a leitura do 
texto, acessando o endereço eletrônico. Em seguida, responderão às questões seguintes: a) explique as funções dos corantes, dos conservantes e dos aromatizantes. b) você acha mais saudável ingerir alimentos naturais ou industrializados? Por quê? Em seguida, um debate deve ser mediado pelo educador para entender a importância dessas substâncias nos alimentos e o perigo do excesso das mesmas.

\section{APLICAÇÃO DO CONHECIMENTO}

Nessa etapa, duas formas de avaliação serão aplicadas, como parte dessa sequência. A primeira delas é uma atividade em grupo, em que os educando produzirão um relatório sobre a aula prática investigativa da qual participaram. Essa atividade deve ser pedida aos alunos logo após a realização da aula prática investigativa, presente no segundo momento pedagógico.

O modelo de relatório pode ser criado pelo educador e repassado para os alunos. É importante que os alunos façam essa atividade com o mesmo grupo de trabalho da aula prática investigativa. Essa tarefa é essencial, já que, conforme nos atenta Carvalho (2010 apud Trazzi et al, 2012, p. 34-35), é preciso que os alunos compreendam o que fizeram na atividade prática, ou seja, "o como conseguiram" e o "porquê"

A outra avaliação será individual, realizada como atividade de casa e receberá o nome de "Agenda da Alimentação". Essa tarefa foi retirada do livro do professor presente no Projeto Araribá - sétima série. Cabe ao educador decidir o tempo que vai sugerir para que os alunos devolvam essa atividade. A seguir, seguem as explicações sobre o roteiro dessa tarefa que será entregue para cada educando.

1. Na primeira página do trabalho, colocar o nome, o título da pesquisa, a data de entrega e a cidade onde se localiza a escola.

2. Recolher, ao longo de uma semana, embalagens (no mínimo CINCO) dos alimentos consumidos em casa ou na escola. Não é necessário colecionar todos, mas os que considerarem mais representativos.

3. Cada embalagem é colada ou grampeada em uma folha de papel sulfite, que deve estar numerada e com a data do consumo do alimento. Embalagens muito grandes podem ser recortadas, colando-se apenas a parte que apresenta o nome e a composição do produto. 
4. 0 diário semanal deve seguir o roteiro "Agenda de alimentação" abaixo.

Quadro 2. Agenda de alimentação (PARA CADA EMBALAGEM DE ALIMENTO).

Dia: Hora : Refeição: (café da manhã, almoço, etc.)

- Alimentos consumidos: (leite, feijão, salgadinho, chocolate, pastel, batata frita, etc.);

- Principal fonte de energia: (ver no rótulo se o alimento tem maior quantidade de carboidratos ou de gorduras);

- Presença de aditivos alimentares:

. Corantes artificiais: $\operatorname{sim}$ não

. Conservantes: sim não

Aromatizantes artificiais: sim não

\section{Quadro 3. Análise dos resultados (NO FINAL DO TRABALHO)}

Cada aluno analisa, a partir das embalagens que coletou, analisará a composição de sua dieta alimentar, respondendo às questões:

a) Que grupo de alimentos compõe a maior parte de sua dieta semanal? Você consome muita gordura? Seus alimentos são mais do tipo "chocolate, salgadinhos e balas" ou "frutas, verduras e cereais"?

b) Sua dieta é semelhante à das outras pessoas da sua casa? Sua família consome mais um tipo de alimentos e você outro?

c) Você conhece doenças que podem ser causadas por uma dieta muito rica em sal e gorduras?

d) Você considera sua dieta saudável? Há muitos aditivos alimentares nos alimentos que compõem sua dieta?

e) 0 que você poderia fazer para tornar seus hábitos alimentares mais saudáveis?

Segundo Zabala (1999 apud LEITE et al, 2012, p. 43), ao se ensinar Ciências Naturais é necessário lançar mão de uma série de conteúdos de diferentes características, denominado por ele de conteúdos da aprendizagem. Esses conteúdos podem ser distribuídos em três grupos: os conteúdos conceituais ("saber"), os procedimentais ("saber fazer") e os atitudinais ("ser"). Ao realizar uma sequência didática no ensino de Ciências é possível articular os conteúdos procedimentais, conceituais e atitudinais, promovendo a ressignificação dos 
conhecimentos prévios (LEITE et al, 2012, p. 43). Assim, entendemos que, ao realizar essa série de atividades com os educandos, o professor tem condições de avaliar esses três tipos de conteúdos.

\section{CONSIDERAÇÕES FINAIS}

Quando analisamos detalhadamente o ensino de Ciências nas nossas escolas, deparamos, frequentemente, com uma metodologia nada atrativa para a construção do saber, em que ocorre uma imensa e desnecessária fragmentação das disciplinas, uma excessiva memorização de conceitos soltos e uma ausência de articulação entre as áreas do conhecimento. Com isso, a ciência passa a ser vista como algo distante da maioria dos nossos educandos e o trabalho dos cientistas é visto como algo fora da realidade da população em geral.

Nesse sentido, defendemos a realização dessa sequência didática para a construção de propostas educacionais orientadas por princípios democráticos e emancipadores, sempre baseados nos interesses da sociedade e articulados com saberes pedagógicos, orientados para a democratização do saber, tomando como base a compreensão histórica da realidade e para o debate sobre os problemas sociais, almejando um ensino de Ciências realmente comprometido com a formação de cidadãos críticos e conscientes, já que o ambiente escolar é o ponto chave para a democratização do conhecimento, buscando uma diminuição da marginalização de grande parte da população. Esse processo levará à alfabetização científica.

Alunos que participam do processo, que argumentam, que interagem, que pesquisam e que têm a sua curiosidade aguçada possuem grandes chances de obter êxito na construção, na desconstrução e na reconstrução dos seus conhecimentos acerca das Ciências. Com isso, mudanças nas atitudes poderão ser observadas. Além disso, acreditamos que a alfabetização científica pode ser considerada como uma das dimensões para potencializar alternativas que privilegiam uma educação mais comprometida com o social. 0 fato é que a alfabetização científica está inserida numa linha emergente na didática das Ciências e é uma possibilidade de fazer correções em ensinamentos distorcidos e fazer com que o aluno entenda as manifestações do universo. Entender a ciência facilita, também, o controle e o monitoramento das transformações do ambiente natural. 
Por fim, acreditamos que as atividades sugeridas durante a utilização dos três momentos pedagógicos propostos por Delizoicov et al. (2011) para a sequência didática em questão configuram-se como uma possibilidade de se estabelecer um ensino dinâmico e dialógico, contribuindo para a construção/reconstrução do conhecimento científico (LEITE et al, 2012, p. 45).

\section{REFERÊNCIAS}

AULER, Decio; DELIZOICOV, Demétrio. Alfabetização científico-tecnológica para quê? ENSAIO Pesquisa em Educação em Ciências. V. 3, n. 1. p. 1-13, Junho, 2001.

AZEVEDO, M. C. P. S. Ensino por investigação: problematizando as atividades de sala de aula. In:

CARVAlHO, Anna Maria Pessoa de. Critérios estruturantes para e ensino das ciências. In: CARVALHO, Anna Maria Pessoa de (org). Ensino de Ciências: Unindo a pesquisa e a prática. São Paulo: Cengage Learning, 2010.

CHASSOT, A. Alfabetização científica: uma possibilidade para a inclusão social. Revista Brasileira de Educação. Jan/Fev/Mar/Abr, n 22, 2003.

DELIZOICOV, Demétrio; ANGOTTI, José A.; PERnAMBUCO M. M.; Ensino de Ciências: Fundamentos e Métodos. 3a edição. São Paulo: Cortez, 2011.

FAVALLI, L., PESSÔA, K.A., ANGELO, E.A. Projeto Radix: ciências, $8^{\circ}$ ano, São Paulo: Scipione, 2010.

FREIRE, P. Pedagogia da autonomia - saberes necessários à prática educativa. São Paulo: Paz e Terra, 2003.

FURIÓ, C., VILVHES, A. GUISASOLA, J., ROMO, V. Finalidades de La enseñanza de lãs ciências em La secundaria obligatoria. Alfabetización científica o propedêutica? Enseñanza de las ciências, v. 19, n.3, p.365-376, 2001.

GIORDAN, M. O papel da experimentação no ensino de Ciências. Química nova na escola. N. 10. Novembro. 1999.

KRASILCHICK, Mirian; MARANDINO, Martha. Ensino de Ciências e Cidadania. $2^{a}$ ed. São Paulo: Editora Moderna, 2007.

LEITE, Sidnei Quezada Meireles; BRASIL, E. D. F.; TERRA V. R.; CASSANI, J.E. Abordagem temática e sequência didática no ensino de Química: construção de uma visão crítica da ciência. In: LEITE, Sidnei Quezada Meireles (org). Práticas experimentais investigativas em ensino de ciências: caderno de experimentos de física, química e biologia - espaços de educação não formal - reflexões sobre o 
ensino de ciências. Vitória : Instituto Federal de Educação, Ciência e Tecnologia do Espírito Santo, 2012.

SANTOS, Wildson L. P.; MORTINER, E. F. Uma análise de pressupostos teóricos da abordagem C. T. S (Ciência, Tecnologia e Sociedade) no contexto da educação brasileira. ENSAIO - Pesquisa em Educação em Ciências. V. 02, n. 02, p. 1 - 23, Dezembro, 2002.

TEIXEIRA, P. M. M. A Educação científica sob a perspectiva da Pedagogia Histórico-Crítica e do movimento C.T.S. no ensino de ciências. Revista Ciências \& Educação, v.9, n.2, p. 177-190, 2003.

TRAZZI, P.S.S.; GARCIA, J.F.M.; SILVA, M. A. J. Ensinar e aprender ciências e biologia: a experimentação em foco. In: LEITE, S. Q. M. Práticas experimentais investigativas em ensino de ciências: caderno de experimentos de física, química e biologia - espaços de educação não formal - reflexões sobre o ensino de ciências. Vitória : Instituto Federal de Educação, Ciência e Tecnologia do Espírito Santo, 2012.

ZABALA, A. A prática educativa. Como ensinar. Artmed, Porto Alegre, 1999.

PROJETO ARARIBÁ. São Paulo: Moderna, $\quad 8^{\text {o }}$ ano, 2008. <http://portaldoprofessor.mec.gov.br/fichaTecnicaAula.html?aula=20840> Acesso em 21/07/2012. 